\title{
Use of Veterans Administration outpatient facilities by older, rural veterans
}

\author{
JOHN C. LICCIARDONE, DO
}

A mail survey was conducted in rural northeastern Missouri to study the factors affecting use of Veterans Administration (VA) outpatient medical services by older veterans. During the year preceding the survey, $39.6 \%$ of the 169 responding veterans had used VA outpatient facilities. Travel time, long waiting time at the clinic, and travel expense were the most common perceived barriers to use. However, these factors were generally poor predictors of use. The reported percentage of each perceived geographic or administrative barrier to use was consistently greater for previous users than for nonusers of these facilities.

Multiple regression analysis revealed private medical insurance coverage to be the only significant predictor of use. Veterans with private medical insurance were more likely to receive ambulatory medical care from local providers than from the VA. The potential impact of removing perceived barriers to use in this population remains unclear.

Part of this study was conducted while the author was affiliated with the Department of Preventive Medicine and Community Health, Kirksville College of Osteopathic Medicine, Kirksville, Mo.

Dr Licciardone is vice-chairman and research director, Department of Public Health and Preventive Medicine, Texas College of Osteopathic Medicine, Fort Worth, TX 76107.

Reprint requests to John C. Licciardone, DO, Department of Public Health and Preventive Medicine, Texas College of Osteopathic Medicine, 3500 Camp Bowie Blvd, Fort Worth, TX 76107.
Factors that affect access to healthcare among the elderly, rural residents, or military veterans have been reported in the literature. However, little is known about the importance of these factors among persons having all three characteristics. In general, access to outpatient healthcare may be influenced by sociodemographic factors, such as age, sex, employment status, income, and medical insurance coverage. Further, access may be limited by geographic constraints, including travel time and travel expense.

It has also been suggested that the effect of these factors on use is less predictable in institutionally based systems of medical care, such as the Veterans Administration (VA), than it is in private practice. ${ }^{1}$ Administrative factors that contribute to the time spent waiting for services at a medical facility and the inability to receive a timely appointment for such services may further affect use. The purpose of the present study was to examine the attitudes of older, rural veterans concerning potential geographic and administrative barriers to use of VA outpatient clinic facilities and to determine the relative importance of these, as well as sociodemographic factors, in predicting use.

\section{Methods}

A mail survey was conducted in a predominantly rural area of northeastern Missouri. This area includes Adair, Knox, Macon, Putnam, Schuyler, Scotland, and Sullivan counties. The study area had an estimated popula- 


\begin{tabular}{|c|c|c|c|c|}
\hline \multicolumn{5}{|c|}{$\begin{array}{c}\text { Table } 1 \\
\text { Sociodemographic Characteristics of } \\
\text { Respondents }\end{array}$} \\
\hline & \multicolumn{2}{|c|}{ Age, yr } & \multicolumn{2}{|c|}{$\begin{array}{l}\text { Annual family income } \\
\text { in } 1985 \text { dollars }\end{array}$} \\
\hline & Mean & SD* & Mean & SD \\
\hline $\begin{array}{l}\text { Users } \\
\qquad(\mathrm{N}=67)\end{array}$ & 61.4 & 9.3 & 18,065 & 8,065 \\
\hline $\begin{array}{l}\text { Nonusers } \\
\quad(\mathrm{N}=102) \\
P \text { value }\end{array}$ & 61.4 & 12.3 & 20,860 & 10,071 \\
\hline
\end{tabular}

tion of $69,500,{ }^{2}$ with no town having a population of 20,000 or greater. In addition, no metropolitan areas were located adjacent to the study area. A total of 108.36 full-time equivalent physicians was located in the study area. Of these, $59.25(54.7 \%)$ practiced primary care medicine. ${ }^{3}$ None of the seven counties included in the survey was designated as a primary care health manpower shortage area. ${ }^{4}$ The nearest VA outpatient clinic was located approximately 90 miles south of the study area.

Survey planning, which incorporated the total design method, ${ }^{5}$ was begun in August 1986. A sample of 275 veterans was selected through member $(\mathrm{N}=221,80.4 \%)$ and nonmember $(\mathrm{N}$ $=54,19.6 \%$ ) rosters of a local Disabled American Veterans organization. A one-page mail questionnaire was developed. Its purpose was threefold: (1) to obtain basic sociodemographic data; (2) to gather information regarding use, as well as perceived barriers to use, of existing VA outpatient facilities; and (3) to determine attitudes concerning prospective use of a proposed VA outpatient clinic within the study area. Questionnaires were mailed in September 1986, and follow-up correspondence was sent to nonrespondents the following month.

Initially, respondents were stratified according to use of VA outpatient facilities during the year preceding the survey. Users and nonusers were compared with respect to sociodemographic characteristics and perceived barariers to use. Comparisons were conducted by using the mean and standard deviation (SD) for age and income. The remaining variables were analyzed by use of the $\chi^{2}$ test with Yates' continuity correction 6 for $2 \times 2$ contingency tables.

Multiple linear regression ${ }^{6}$ was also used to further study the relationship between reported VA outpatient clinic use and the following predictor variables: age, sex, annual family income, medical insurance coverage (private, Medicare, and Medicaid), and perceived barriers to use (travel time, travel expense, long waiting time at the clinic, and inability to receive a timely clinic appointment). All predictor variables were dichotomized with the exception of age and income, which were entered as continuous and categorical variables, respectively.

\section{Results}

Forty of the original 275 questionnaires were not deliverable. Of the remaining 235 eligible subjects, $169(71.9 \%)$ responded. Reporting on questionnaire items among respondents was virtually complete (98.9\%). Overall, the respondents' mean age was 61.4 years $(\mathrm{SD} \pm 11.2$ years). Most respondents were male (98.2\%), and most were married ( $83.2 \%)$ and homeowners $(89.4 \%)$. The 1985 mean annual family income, before taxes, was $\$ 19,742$ (SD $\pm \$ 9,269$ ).

A majority of respondents also had private medical insurance $(53.3 \%)$ in addition to VA benefits; $43.2 \%$ reported having Medicare insurance, and $7.1 \%$ had Medicaid insurance. None of the respondents was a member of a health maintenance organization or a preferred provider organization.

The respondents' sociodemographic characteristics according to previous VA outpatient clinic use are summarized in Tables 1 and 2 . Previous users $(\mathrm{N}=67)$ and nonusers $(\mathrm{N}=$ 102) of VA facilities were similar with respect to age, sex, and marital status. However, trends toward higher employment $(P=.07)$ and greater annual family income $(P=.06)$ were observed in nonusers. The greater proportion of private medical insureds among nonusers compared with users was highly significant $(P=.0004)$. The proportions of Medicare $(P=.74)$ and Medicaid $(P=.29)$ insureds 
Table 2

Sociodemographic Characteristics of Respondents, Continued

\begin{tabular}{|c|c|c|c|c|c|}
\hline \multirow[b]{2}{*}{ Variable } & \multicolumn{2}{|c|}{ Users $(N=67)$} & \multicolumn{2}{|c|}{ Nonusers $(N=102)$} & \multirow[b]{2}{*}{$P$} \\
\hline & No. & $\%$ & No. & $\%$ & \\
\hline \multicolumn{6}{|l|}{ Sex } \\
\hline Male & 66 & 98.5 & 100 & 98.0 & \\
\hline Female & 1 & 1.5 & 2 & 2.0 & .71 \\
\hline \multicolumn{6}{|c|}{ Marital status } \\
\hline Married & 55 & 83.3 & 84 & 83.2 & \\
\hline Unmarried & 11 & 16.7 & 17 & 16.8 & .85 \\
\hline \multicolumn{6}{|c|}{ Employment status } \\
\hline Employed & 17 & 26.2 & 43 & 43.0 & \\
\hline Unemployed & 8 & 12.3 & 7 & 7.0 & \\
\hline Retired & 40 & 61.5 & 50 & 50.0 & .07 \\
\hline \multicolumn{6}{|c|}{$\begin{array}{l}\text { Medical insurance } \\
\text { coverage }\end{array}$} \\
\hline Private & 24 & 35.8 & 66 & 64.7 & .0004 \\
\hline Medicare & 27 & 41.8 & 45 & 44.1 & .74 \\
\hline Medicaid & 7 & 10.5 & 5 & 4.9 & .29 \\
\hline
\end{tabular}

among users and nonusers were not significantly different.

A bimodal distribution was observed for frequency of VA outpatient clinic use, with 102 respondents $(60.4 \%)$ not having visited the clinic during the year preceding the survey. The distribution of respondents among the remaining use categories was as follows: 1 to 2 visits, $18(10.7 \%) ; 3$ to 6 visits, $32(18.9 \%) ; 7$ to 12 visits, $11(6.5 \%)$; and more than 12 visits, $6(3.5 \%)$. A mean of 5.4 visits per year was observed among the users of VA outpatient facilities.

The distribution of perceived barriers to VA outpatient clinic use was as follows: travel time, $117(69.2 \%)$; long waiting time at the clinic, 80 (47.3\%); travel expense, 74 (43.8\%); inability to receive a timely clinic appointment, 18 (10.7\%); and all others, 15 (8.9\%). (The total percentage of perceived barriers exceeds $100 \%$ because some respondents cited multiple barriers.)

The perceived barriers to use according to previous VA clinic attendance are summarized in Table 3. Although no significant differences in perceived barriers to use existed between users and nonusers, the reported percentage of each barrier was greater among clinic users than among nonusers. A total of 147 respondents $(87.0 \%)$ indicated that they would use a VA clinic within the study area; 21 $(12.4 \%)$ were unsure that they would use such a clinic, and only $1(0.6 \%)$ would definitely not use a VA clinic in the study area. No significant difference was found in the projected use of a VA clinic in the study area between users and nonusers of existing VA clinic facilities. However, use was projected to be slightly greater among current users $(91.0 \%)$ than among nonusers $(84.3 \%)$.

The multiple regression coefficients for predicting VA clinic use are presented in Table 4. Annual family income, private medical insurance coverage, Medicare insurance coverage, and travel expense were all inversely related to use. Of the four factors, however, only private medical insurance coverage was a significant predictor of use $(P=.0005)$. None of the predictor variables displayed a significant direct relationship to use.

\section{Discussion}

Among the survey sample of older veterans residing in rural northeastern Missouri, 39.6\% 


\begin{tabular}{|c|c|c|c|c|c|}
\hline \multicolumn{6}{|c|}{$\begin{array}{c}\text { Table } 3 \\
\text { Perceived Barriers to Use of Veterans Administration } \\
\text { Outpatient Facilities }\end{array}$} \\
\hline \multirow[b]{2}{*}{ Variable } & \multicolumn{2}{|c|}{ Users $(N=67)$} & \multicolumn{2}{|c|}{ Nonusers $(N=102)$} & \multirow[b]{2}{*}{$\boldsymbol{P}$} \\
\hline & No. & $\%$ & No. & $\%$ & \\
\hline Travel time & 42 & 77.6 & 65 & 63.7 & .98 \\
\hline Travel expense & 33 & 49.3 & 41 & 40.2 & .32 \\
\hline $\begin{array}{l}\text { Long waiting time } \\
\text { at the clinic }\end{array}$ & 38 & 56.7 & 42 & 41.2 & .07 \\
\hline $\begin{array}{l}\text { Inability to re- } \\
\text { ceive a timely } \\
\text { clinic appointment }\end{array}$ & 10 & 14.9 & 8 & 7.8 & .23 \\
\hline Others & 7 & 10.5 & 8 & 7.8 & .76 \\
\hline
\end{tabular}

reported use of VA outpatient facilities during the year preceding the survey. This was in marked contrast to the 1978 Health Interview Survey in which only $4.3 \%$ of veterans reported use of any VA healthcare facilities. ${ }^{7}$ No doubt, much of this discrepancy in use may be attributed to the high prevalence of serviceconnected disability as well as the older age distribution of veterans in the present survey.

However, the results also suggest the potential for improved access to VA healthcare for this population. In the present survey, rural veterans reported a mean of 5.4 outpatient visits per year. This compares with 6.7 visits per year among similarly aged patients attending a VA medical center in a large metropolitan area. ${ }^{8}$ Also, the desirability of a local VA facility was substantiated by the $87.0 \%$ of the respondents to the Missouri survey who claimed they would use such a facility.

Travel time was the most prevalent perceived barrier to VA use in northeastern Missouri, followed by long waiting time at the clinic and travel expense. Inability to obtain a timely clinic appointment and other miscellaneous factors did not appear to be important barriers to use.

The reported percentage of each perceived barrier was greater in users than in nonusers of the facilities. This suggests that these barriers were not, in fact, strong deterrents to clinic use. The results of multiple linear regression provided further confirmation. Travel time, long waiting time at the clinic, and inability to receive a timely clinic appointment were all directly related to use. Only travel expense was inversely related to use, although this relationship was weak.

Despite these reported geographic and administrative barriers, use of VA facilities among older veterans in northeastern Missouri appears to be much more sensitive to medical insurance coverage. This finding agrees with those of previous investigations that surveyed veterans with diverse sociodemographic and residential characteristics. ${ }^{7,9}$ Similar results have also been reported among nonveterans from a rural population. ${ }^{10}$ As in these previous studies, age and income in the present study were relatively poor predictors of use.

Overall, the results of this survey suggest that older, rural veterans generally travel long distances at considerable expense to receive VA medical care. The study area had a low population-to-physician ratio and was not designated as a health manpower shortage area ${ }^{4}$; therefore, it appears unlikely that veterans traveled to VA facilities because of a physician shortage in the study area. Generally, veterans with private medical insurance and, to a lesser extent, those with Medicare coverage, received ambulatory medical care from local providers rather than through VA facilities.

It has been observed elsewhere that veterans often travel longer distances to visit VA facilities than to see their personal physicians. ${ }^{1}$ Aside from medical insurance coverage and ability-to-pay considerations, it has been suggested that lack of local specialty consultants and the unavailability of nearby sophis- 


\begin{tabular}{|c|c|c|c|}
\hline \multicolumn{4}{|c|}{$\begin{array}{l}\text { Table } 4 \\
\text { Regression Coefficients for Predicting Use } \\
\text { of Veterans Administration Outpatient Facilities }\end{array}$} \\
\hline \multirow[b]{2}{*}{ Independent variable } & \multicolumn{3}{|c|}{ Use } \\
\hline & Coefficient & SE* & $P$ \\
\hline Age & 0.0082 & 0.0106 & .44 \\
\hline Sex $($ female $=0$, male $=1)$ & 0.2395 & 0.6816 & .73 \\
\hline Annual family income & -0.0209 & 0.1144 & .86 \\
\hline \multicolumn{4}{|l|}{ Medical insurance coverage ${ }^{\dagger}$} \\
\hline Private & -0.7164 & 0.1996 & .0005 \\
\hline Medicare & -0.2981 & 0.2287 & .19 \\
\hline Medicaid & 0.3917 & 0.3908 & .32 \\
\hline \multicolumn{4}{|l|}{ Perceived barriers to use ${ }^{\dagger}$} \\
\hline Travel time & 0.2801 & 0.2371 & .24 \\
\hline Travel expense & -0.0558 & 0.2228 & .80 \\
\hline Long waiting time at the clinic & 0.0931 & 0.2186 & .67 \\
\hline $\begin{array}{l}\text { Inability to receive } \\
\text { a timely clinic } \\
\text { appointment }\end{array}$ & 0.5745 & 0.3066 & .06 \\
\hline
\end{tabular}

ticated diagnostic technology may explain the use of more distant VA facilities. ${ }^{11,12}$ Indeed, portions of the study area were designated as shortage areas for dental, vision, and podiatric health manpower. ${ }^{4}$ However, the use of local ambulatory services by veterans with private medical insurance coverage suggests that the study area had access to adequate medical specialty services and diagnostic technology.

None of the survey respondents was a member of a health maintenance organization or preferred provider organization. This factor indicates that such medical care systems likely will have little influence on veterans' choices for medical services in this area in the near future.

A mobile clinic has been introduced in rural Colorado to improve veterans' access to medical care. ${ }^{13}$ This outreach program improved access for veterans (mean age $=56$ years, $97 \%$ male) residing more than 50 miles from a VA medical center. Further, the cost for these services compares favorably with fees for conventional outpatient visits. The results of the Missouri survey suggest that such an outreach program may be potentially useful in rural northeastern Missouri.

Several factors regarding the methods used in this survey deserve comment. The sampling frame consisted of member and nonmember rosters of a local Disabled American Veterans organization. Because nonroster veterans were not sampled and their sociodemographic characteristics were unknown, the possibility of selection bias cannot be adequately assessed. The results of this study may not lend themselves to generalization because of the high prevalence of service-connected disability among veterans surveyed. Likewise, $28.1 \%$ of the veterans sampled did not respond to either of two requests for information. Hence, these veterans' characteristics remain unknown. Although this nonresponse rate approximates that of other mail surveys using the total design method, ${ }^{5}$ the possibility of nonresponse bias cannot be dismissed. Finally, individual data were unavailable for variables such as service-connected disability ${ }^{7,14}$ and health 
status, ${ }^{10,15}$ which are viewed as important predictors of outpatient use.

Despite these limitations, the survey demonstrates that the factors affecting older, rural veterans' use of VA outpatient facilities are similar to those found among younger veterans and veterans from diverse residential settings. Service-connected disability is a strong positive predictor of use, and private medical insurance coverage is a strong negative predictor. The potential impact of removing perceived geographic and administrative barriers to use-by establishing a satellite clinic in the study area, for example-remains unclear.

\section{Summary}

The results of this survey indicate that users and nonusers of VA outpatient facilities tend to be similar with respect to age, sex, marital status, and Medicare and Medicaid insurance coverage. Nonusers are more likely to be employed, to have a greater annual family income, and to have private medical insurance coverage.

Although older, rural veterans frequently cite travel time, long waiting time at the clinic, and travel expense as barriers to use, none of these factors is a significant predictor of use. Private medical insurance coverage appears to be the only significant predictor (a negative one) of use. Thus, the potential impact of removing perceived barriers to use for this population remains unclear.
The author wishes to express his gratitude to the veterans who participated in this survey.

1. Manu P, Calder EA, Goodspeed RB: How many miles to the VA doctor? Letter. $N$ Engl J Med 1984;310:929-930.

2. Missouri Population Estimates: 1980-1984. Missouri Department of Health. Jefferson City, Mo. Missouri Center for Health Statistics publication No. 8.9, 1986.

3. Missouri Health Manpower: 1983. Missouri Department of Social Services. Jefferson City, Mo, Missouri Center for Health Statistics publication No. 2. 16, 1984.

4. Lee RC: Designation of health manpower shortage areas for use by Public Health Service programs. Public Health Rep 1979;94:48-59.

5. Dillman DA: Mail and Telephone Surveys: The Total Design Method. New York, John Wiley \& Sons, 1978.

6. Rosner B: Fundamentals of Biostatistics. Boston, Duxbury Press, 1982.

7. Wolinsky FD, Coe RM, Mosley RR, et al: Veterans' and nonveterans' use of health services: A comparative analysis. Med Care 1985;23:1358-1371.

8. Charles G, Stimson DH: Use of ambulatory care resources by Medicare-age patients in a primary care group practice. $J$ Am Geriatr Soc 1987;35:489-495.

9. Page WF: Why veterans choose Veterans Administration hospitalization: A multivariate model. Med Care 1982;20:308-320.

10. Berk ML, Bernstein AB, Taylor AK: The use and availability of medical care in health manpower shortage areas. Inquiry 1983;20:369-380.

11. Williams AP, Schwartz WB, Newhouse JP, et al: How many miles to the doctor? $N$ Engl J Med 1983;309:958-963.

12. Williams AP, Schwartz WB, Newhouse JP, et al: How many miles to the VA doctor? Letter. N Engl J Med 1984;310:930.

13. Oboler SK, Blieden MA, Carter SA, et al: A mobile internal medicine clinic. Arch Intern Med 1983;143:97-99.

14. Hammond D: National Survey of Veterans: Summary Report. Washington, DC, Veterans Administration, Office of Controller, 1980.

15. Romeis JC, Gillespie KN, Coe RM: Older veterans' future use of VA health care services. Med Care 1988;26:854-866. 


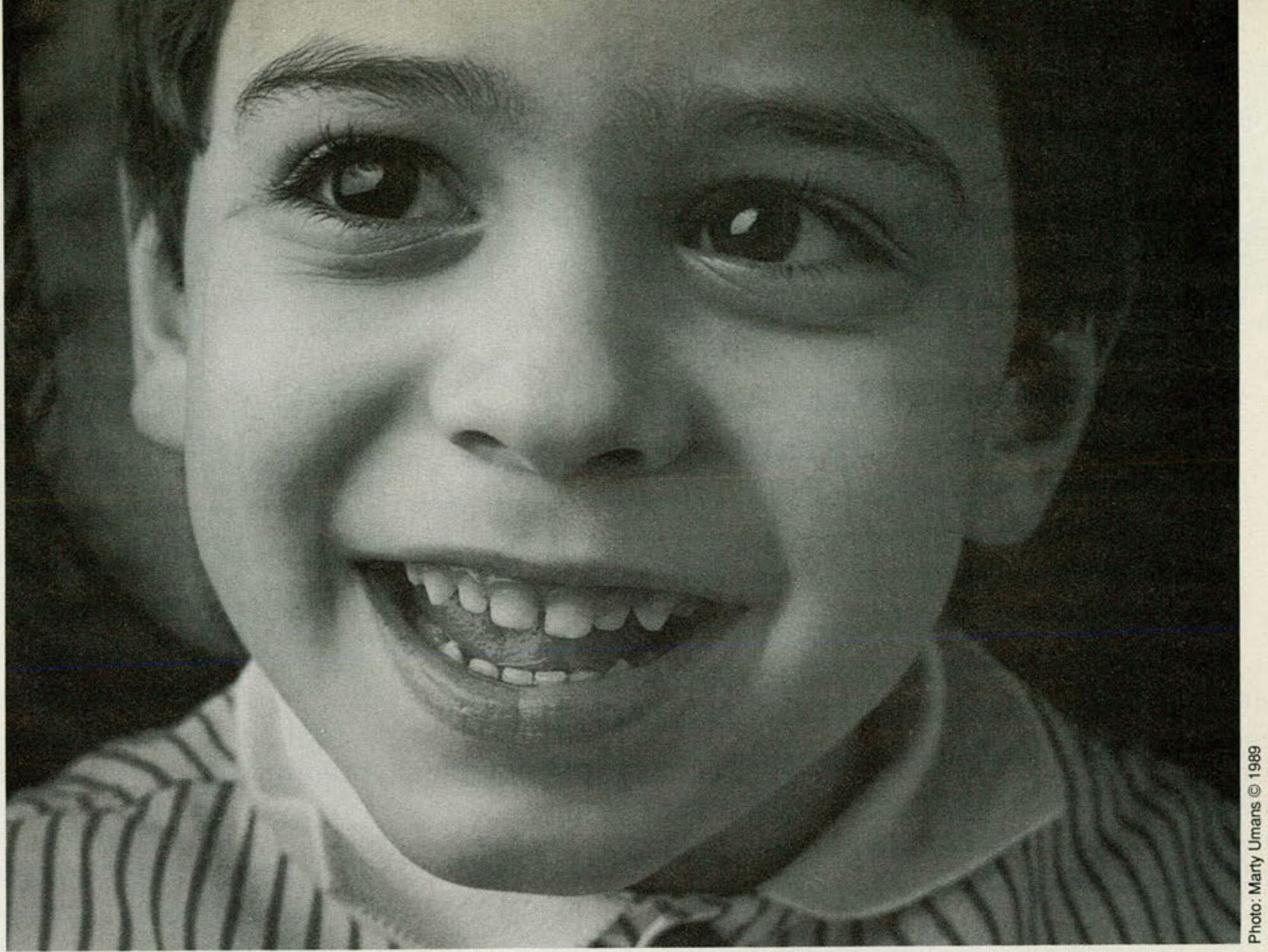

\section{THE FIRST PART OF THE BODY THAT MUSCULAR DYSTROPHY AFFECTS.}

It's hard to smile when you lose the ability to walk. To play. To draw pictures. To climb a tree.

But that's what happens when a child has muscular dystrophy.

"Muscular dystrophy" is the name for a group of diseases that weaken and destroy the muscles. The disorders are progressive, so things get worse over time. The muscle loss can't be stopped. And it can't be reversed.

The Muscular Dystrophy Association is striving to cure muscular dystrophy. And on Christmas Eve of 1987, MDA researchers announced a landmark advance: discovery of the cause of the most terrible form of muscular dystrophy, Duchenne.

Now a giant step toward curing these dread diseases has been taken. And MDA researchers are forging ahead, racing to save the children stricken today.

MDA receives no government grants or fees for services - its work is funded entirely by private donations. You can help MDA fight muscular dystrophy and dozens of other muscle diseases by sending a tax-deductible contribution today.

Don't wait until a child's smile reminds you of all the children who have stopped smiling. Please send your donation today.

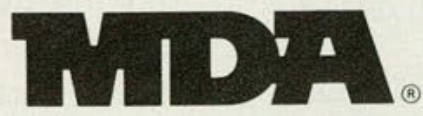

Muscular Dystrophy Association, Jerry Lewis, National Chairman 